\title{
Insight in bipolar disorder: relationship to episode subtypes and symptom dimensions
}

\author{
This article was published in the following Dove Press journal: \\ Neuropsychiatric Disease and Treatment \\ 20 September 2010 \\ Number of times this article has been viewed
}

\section{Frederick Cassidy}

Duke University, Durham, NC, USA

Correspondence: Frederick Cassidy Central Regional Hospital, 300 Veazy

Road, Butner, NC 27509, USA

Tel +l 919575 780 I

Email cassi002@mc.duke.edu
Background: The study of insight in bipolar disorder has received limited attention, despite its potential impact on treatment compliance and prognosis. In the current study we compare insight levels during different phases of bipolar disorder, and consider its relationship to symptoms dimensions and epidemiologic variables.

Methods: Insight ratings obtained from 156 bipolar subjects in any phase of bipolar disorder were compared. A regression analysis was also conducted to identify symptom dimensions predictive of insight levels.

Results: Greater impairments in insight were observed during pure manic episodes than during mixed or depressed episodes, or during euthymia. Depressive symptoms were associated with better insight. Improvements in insight with treatment were neither complete nor universal. Lack of insight was unrelated to age, years of illness, age of first psychiatric illness, or lifetime number of hospitalizations.

Conclusions: Although psychosis may be associated with impaired insight, other variables also impact on degree of impaired insight. Specifically, depressed mood appears to be associated with preservation of insight. That relationship may transcend strict syndromal diagnosis.

Keywords: insight, bipolar disorder, psychosis, depression

\section{Introduction}

The study of insight in mood disorders has traditionally received limited attention, despite its possible impact on both treatment compliance and outcome. ${ }^{1-3}$ Although impaired insight has been a focus of study in schizophrenia ${ }^{4-10}$ and depression, ${ }^{11,12}$ it has been less well studied in bipolar disorder. Studies in bipolar cohorts, however, confirm that lack of insight is frequently observed in that disorder as well. ${ }^{13-15}$

Relationships between poor insight and particular symptoms or symptom clusters have also been suggested. One early study suggested a relationship of grandioseeuphoria dimension with poor insight in schizophrenia. ${ }^{16}$ Preserved insight has also been observed with depressive symptoms in studies that have focused largely on unipolar major depression, ${ }^{11,12}$ schizophrenia/schizoaffective disorder, ${ }^{4,5,7-10}$ and mixed mania. ${ }^{13}$ Impaired insight and psychotic symptoms are also strongly associated with each other. Although this intuitive association is supported by face-validity, it is important to observe that the two constructs are neither synonymous, nor inextricably linked.

Although a few studies indicate that the degree of insight impairment may be state dependent, ${ }^{17}$ resolution of the acute affective state or associated psychosis, neither assures nor stipulates that impairment in insight will fully resolve. Varga et al ${ }^{15}$ reported a 94\% prevalence of impaired insight in symptomatic depressed, manic, and 
subsyndromal bipolar I patients, compared with $47 \%$ in remitted patients. Yen et al ${ }^{14}$ prospectively observed decreased insight during mania compared with euthymia. Insight following either a single manic or depressed episode was similar to pre-episode insight but remained at least partially impaired in a small group of six subjects who had experienced multiple episodes during a two-year period.

In the current study we examine insight in a specifically bipolar cohort that is observed in all phases of the illness (eg, manic, mixed, depressed, and euthymic). We test for state differences in impaired insight, as well as associations of impaired insight with particular symptom dimensions and course.

\section{Material and methods}

Prospectively-obtained ratings and histories of all subjects evaluated meeting DSM-IV (Diagnostic and Statistical Manual of Mental Disorders, 4th Edition) criteria for bipolar disorder (manic, mixed, depressed, and euthymic) and had been evaluated with the Scale for Manic States (SMS) ${ }^{18}$ were identified in our bipolar database. All subjects had given written consent to participate in one or more study of bipolar disorder and at the time of evaluation met DSM-IV criteria for any phase of bipolar disorder (manic, mixed, depressed, and euthymic). In an Institutional Review Board-approved process, data were then transferred to a larger database for further subsequent analyses. All subjects were in-patients at John Umstead Hospital, Butner, North Carolina at the time of evaluation. The SMS is a 20-item observer-rated scale for bipolar disorder including symptoms drawn from a range of symptoms. Factor analyses of scale ratings demonstrated that symptoms relate to five independent symptom dimension: depressed mood, psychomotor pressure, psychosis, irritability-paranoia, and hedonic drive. ${ }^{19}$ The related SMS subscales allow for the dimensional assessment of symptoms during affective episodes and have been used to supplement categorical assessment. ${ }^{20,21}$ The scale's reliability and validity are reported elsewhere. ${ }^{18}$ Manic and mixed episode subtypes were defined using a definition obtained from receiver operating characteristic analysis. ${ }^{22}$ That definition provides a more specific and less restrictive alternative to the current DSM-IV nomenclature for mixed mania and has been validated using epidemiologic variables ${ }^{21,23-25}$ and biomarkers. ${ }^{26,27}$

An initial analysis of variance (ANOVA) with post-hoc Scheffe-corrected comparisons was conducted to test for differences in impaired insight scores (SMS item 13) between the diagnostic categories. Impaired insight (SMS item 13) represents a composite of denial of illness and rejection of treatment. ANOVAs were conducted testing for differences in general psychosis (SMS item 10), age, age of first psychiatric hospitalization, lifetime number of psychiatric hospitalization, and years of illness since first psychiatric hospitalization between diagnostic groups. Possible differences in gender and race between the groups were also assessed using chi-squared statistics. If any of these variables were significant across the diagnostic groups, they were included as covariants in the final ANOVA comparing insight between the same diagnostic groups. ANOVA's were also conducted testing for gender and race interactions with insight in the overall group. Only initial ratings of subjects evaluated both during an acute episode and following remission were included from the initial between group comparisons to avoid violations of independence in the analyses. To test for possible relationship between insight scores and lifetime severity measures, Pearson correlation coefficients were computed between lack of insight score (SMS item 13) and other clinical variables (current age, age of first psychiatric hospitalization, years since first psychiatric hospitalization, and number of lifetime psychiatric hospitalizations). In a separate analysis to test for state dependence of impaired insight between acute episodes and remission, insight scores for a subset of subjects evaluated during both phases were compared using paired t-tests.

Subscale factor scores were computed by addition of relevant items from the SMS to quantify individual symptom dimensions for rating during the manic, mixed, depressed, and euthymic states, based on a factor analysis in a separate data set. ${ }^{19}$ The constituent symptoms for Factor 1 representing dysphoria were depressed mood, anxiety, guilt, suicidality, and mood lability. Factor 2, representing psychomotor pressure, included motor activity, racing thought, pressured speech, and increased interpersonal contact. Factor 3, representing psychosis, was calculated as the sum of general psychosis, paranoia, and grandiosity. The insight item from the SMS, which in previous studies was also included in this factor, was excluded to avoid an a priori association. Factor 4, reflecting hedonic drive, included grandiosity, euphoria, humor, and hypersexuality. Factor 5 comprised paranoia, irritability, and aggression. A logistic regression was conducted with insight score as the dependent variable, and each of the factor scores as independent variables.

\section{Results}

Ratings of 156 subjects were obtained. Eighty-six were evaluated during pure manic episodes, 29 during mixed manic episodes, 14 during bipolar depressed episodes, and 27 in remission. The sample included 86 males and 70 females. 
Ninety-five were white and 61 were black. Their mean age was 41.5 years (standard deviation [SD] 11.8, range 18-70). Subjects had an average of 7.7 (SD 8.4) lifetime psychiatric hospitalizations, had been ill 14.8 (SD 12.4) years since their first hospitalization, and had a mean age at first psychiatric hospitalization of 28.8 (SD 11.0) years.

Differences between lack of insight scores were noted between diagnostic groups $(\mathrm{F}=16.8, P<0.001)$. The mean lack of insight score of the pure manic group (2.395, SD $1.625)$ was significantly greater than the mean of the mixed manic group $(1.345, \mathrm{SD} 1.495, P=0.012)$, bipolar depressed group $(0.571, \mathrm{SD} 0.852, P<0.001)$, and the euthymic group (0.444, SD 0.934, $P<0.001)$. No group differences were observed between the mixed manic, bipolar depressed, or bipolar euthymic groups.

Differences in general psychosis scores were also observed across the diagnostic groups in a separate ANOVA $(\mathrm{F}=23.179, P<0.001)$. Both the pure manic group $(2.86, \mathrm{SD}$ $1.595)$ and mixed manic group (2.276, SD 1.771) had greater mean psychosis scores than the euthymic group $(0.185, \mathrm{SD}$ 0.483 ), but did not differ from each other. In addition the general psychosis scores in the pure manic group (2.86, SD 1.595) were greater than in the bipolar depressed group (1.429, SD $1.505, P=0.013)$. Other group comparisons of psychosis were not significant (ns). No between group differences were noted for age $(\mathrm{F}=1.136, \mathrm{~ns})$, number of lifetime psychiatric hospitalizations $(\mathrm{F}=0.068, \mathrm{~ns})$, age of first psychiatric hospitalization $(\mathrm{F}=0.264, \mathrm{~ns})$, or length of illness since first psychiatric hospitalization $(\mathrm{F}=0.238, \mathrm{~ns})$. Impaired insight scores were lower in whites (1.305, SD 1.530) than African Americans (2.311, SD 1.669, $\mathrm{F}=14.958, P<0.001)$, and a trend was also noted for lower scores in females (1.443, SD 1.529) than males (1.907, SD 1.733, $\mathrm{F}=3.073, P=0.08)$. Using chi-squared statistics, overall differences were also noted for race $\left(\chi^{2}=20.2\right.$, degrees of freedom $\left.[\mathrm{df}]=3, P<0.001\right)$ and gender $\left(\chi^{2}=9.3\right.$, df $\left.=3, P<0.05\right)$ between the diagnostic groups. When the ANOVA was conducted comparing lack of insight across the four diagnostic groups, including general psychosis, gender, and race as a covariates, overall differences in lack of insight were maintained ( $\mathrm{F}=4.007, P=0.009)$. Psychosis scores remained relevant to the lack of insight score $(\mathrm{F}=21.1, P<0.001)$, however gender $(\mathrm{F}=0.112)$ and race $(\mathrm{F}=3.293)$ effects were not observed.

Lack of insight was not significantly correlated with current age $(r=0.069)$, lifetime number of psychiatric hospitalization $(r=-0.044)$, age of first psychiatric hospitalizations $(r=0.013)$, or years of illness since first psychiatric hospitalization $(\mathrm{r}=0.054)$.
The regression for the prediction of lack of insight from manic rating factor scores was significant $(\mathrm{F}=31.123$, $P<0.001$, R-squared $=0.509$ ). Four factors were significant in the regression model for the prediction of lack of insight. Psychosis, psychomotor pressure, and irritable-aggression scores were positively related to impaired insight (Table 1), while higher levels of depressive symptoms were predictive of better insight. The remaining factor, hedonic drive, was not significant.

Seventeen subjects evaluated in mixed (10) or pure (7) manic episodes were reevaluated following remission. Mean lack of insight scores were higher (2.176, SD 1.912) during the acute episodes than during remission $(0.412$, SD 0.795 , $\mathrm{t}=3.85, \mathrm{df}=16, P<0.001)$. Four of the 12 subjects who had lack of insight scores of one or greater during mixed or pure episodes, defined as moderate or greater impairment, continued to have scores in that range following remission.

\section{Discussion}

Impaired insight is frequently observed in patients with bipolar disorder, particularly during pure manic episodes. Fully 73 of $86(84.9 \%)$ subjects during pure mania had insight scores of one or greater, indicating at least a moderate denial of illness. Although less common during other episodes, moderate denial of illness was nonetheless noted in 17 of $29(58.6 \%)$ of subjects during mixed manic episodes, five of 14 (35.7\%) during bipolar depressed episodes and six of 27 (22.2\%) during euthymia.

In our initial analyses possible racial and gender differences in insight scores were noted. When insight scores across diagnostic groups were compared, including these two covariates, however, neither remained significant. Hence, gender and racial differences may be explained by differences in distribution of the different diagnostic groups. In previous studies we have observed an association of mixed manic episodes with both female gender and white race ${ }^{25}$ compared with pure manic episodes.

Received wisdom usually associates lack of insight with increased psychosis, which is an intuitive connection.

Table I Regression analysis of symptom dimension for the prediction of impaired insight

\begin{tabular}{llll}
\hline Variable & $\boldsymbol{\beta}$ & $\boldsymbol{P}$ & $\begin{array}{l}\text { 95\% confidence } \\
\text { interval }\end{array}$ \\
\hline Dysphoria & -0.130 & 0.034 & $-0.106--0.004$ \\
Psychomotor agitation & 0.208 & 0.029 & $0.007-0.129$ \\
Psychosis & 0.247 & 0.006 & $0.029-0.170$ \\
Hedonic drive & -0.124 & 0.176 & $-0.117-0.022$ \\
Irritable aggression & 0.423 & $<0.001$ & $0.171-0.409$ \\
\hline
\end{tabular}


Most relevant studies have confirmed that observation in schizophrenia/schizoaffective disorder ${ }^{4-7}$ and mixed diagnostic cohorts. ${ }^{11}$ Our data confirms that association as well in an exclusively bipolar cohort. Impaired insight, however, is not predicated on psychosis alone. Whether viewed syndromally or dimensionally, depression appears to be relevant to the preservation of insight during acute episodes. Ratings of insight during bipolar depression and mixed states, both states characterized by depressive features, showed less impairment in insight than ratings during pure manic states, even with the inclusion of statistical adjustments for differing degrees of concurrent psychosis. Moreover, depressive symptoms, independent of episode diagnosis, were a negative predictor of impaired insight across the entire cohort. These findings are in consonance with studies that have focused largely on unipolar major depression ${ }^{11,12}$ and schizophrenia/schizoaffective disorder, ${ }^{4,5,7-10}$ and a previous earlier independent study that compared only mixed and pure manic states exclusively. ${ }^{13}$ Viewed collectively, the relationship of depression to insight appears to transcend strict syndromal diagnosis.

Previous researchers have also suggested that a grandioseeuphoria dimension might be related with poor insight in schizophrenia, ${ }^{16}$ although never clearly substantiated. Our study, too, does not suggest a relationship. Hedonic drive, including euphoria and grandiosity, as well as hypersexuality and humor, was not predictive of poor insight. Hence, it appears that it is the degree of dysphoria, rather than euphoria, that is essential to level of insight observed during acute bipolar episodes.

Psychomotor agitation and irritability were also predictive of lack of insight during acute episodes. Both represent core features of mania and may reflect overall severity during manic episodes. Impaired insight in a hospitalized cohort might also tend to foster irritability, or at least its manifestation. Correlations between longitudinal severity markers (eg, length of illness since first hospitalization, age of first hospitalization, number of lifetime psychiatric hospitalizations), however, were not significant in these analyses. Hence, in this small naturalistic study, it did not appear that insight either improved with length of illness or number of hospitalizations, or worsened with a prolonged or deteriorating course. Whether these two factors in some way may counterbalance the effect of each other is unclear.

Impaired insight is sometimes naively regarded as a secondary measure emanating from psychotic symptomatology and tracking with global illness severity. Under that paradigm, insight would improve as primary symptoms improve. Although improvement in insight was observed with treatment, that improvement was neither universal nor complete, again highlighting the dissociation of constructs.

Some limitations to the study should be noted. The cohort comprised exclusively hospitalized subjects and recruitment bias may have impacted the study given the potential for subjects with less insight to be less willing to participate in research studies. Our measure of insight was extracted from a scale item focusing on global insight and acceptance of treatment.

Nonetheless, the importance of insight in bipolar disorder is obvious. It is relevant both during acute bipolar episodes and during remission. It may impact on acceptance of treatments during acute phases of the illness, as well as on compliance with prophylactic treatment and recognition of early warning signs of relapse.

\section{Conclusion}

Impaired insight is common in bipolar disorder and may impact on compliance and treatment outcome. Although insight may, to some degree, be state-dependent, impairments can persist following resolution of other symptomatology. Psychosis, although distinct from impaired insight, is positively associated with it, while depression has a negative association. Psychomotor acceleration and irritability, both core features of mania, were also associated with poor insight.

\section{Disclosure}

The author reports no conflicts of interest in this work.

\section{References}

1. Copeland LA, Zeber JE, Salloum IM, Pincus HA, Fine MJ, Kilbourne AM. Treatment adherence and illness insight in veterans with bipolar disorder. J Nerv Ment Dis. 2008;196(1):16-21.

2. Ghaemi SN, Boiman E, Goodwin FK. Insight and outcome in bipolar, unipolar, and anxiety disorders. Compr Psychiatry. 2000;41(3):167-171.

3. Yen CF, Chen CS, Ko CH, et al. Relationships between insight and medication adherence in outpatients with schizophrenia and bipolar disorder: prospective study. Psychiatry Clin Neurosci. 2005;59(4):403-409.

4. Kemp RA, Lambert TJ. Insight in schizophrenia and its relationship to psychopathology. Schizophr Res. 1995;18(1):21-28.

5. Smith TE, Hull JW, Israel LM, Willson DF. Insight, symptoms, and neurocognition in schizophrenia and schizoaffective disorder. Schizophr Bull. 2000;26(1):193-200.

6. Collins AA, Remington GJ, Coulter K, Birkett K. Insight, neurocognitive function, and symptom clusters in chronic schizophrenia. Schizophr Res. 1997;27(1):37-44.

7. McEvoy JP, Johnson J, Perkins D, et al. Insight in first-episode psychosis. Psychol Med. 2006;36(10):1385-1393.

8. Drake RJ, Pickles A, Bentall RP, et al. The evolution of insight, paranoia, and depression during early schizophrenia. Psychol Med. 2004;34(2):285-292.

9. Iqbal Z, Birchwood M, Chadwick P, Trower P. Cognitive approach to depression and suicidal thinking in psychosis. 2. Testing the validity of a social ranking model. Br J Psychiatry. 2000;177:522-528. 
10. Markova IS, Berrios GE. The assessment of insight in clinical psychiatry: a new scale. Acta Psychiatr Scand. 1992;86(2):159-164.

11. Sanz M, Constable G, Lopez-Ibor I, Kemp R, David AS. A comparative study of insight scales and their relationship to psychopathological and clinical variables. Psychol Med. 1998;28(2):437-446.

12. Peralta V, Cuesta MJ. Lack of insight in mood disorders. JAffect Disord. 1998;49(1):55-58.

13. Cassidy F, McEvoy JP, Yang YK, Wilson WH. Insight is greater in mixed than in pure manic episodes of bipolar I disorder. J Nerv Ment Dis. 2001;189(6):398-399.

14. Yen CF, Chen CS, Ko CH, Yen JY, Huang CF. Changes in insight among patients with bipolar I disorder: a 2-year prospective study. Bipolar Disord. 2007;9(3):238-242.

15. Varga M, Magnusson A, Flekkoy K, Ronneberg U, Opjordsmoen S. Insight, symptoms, and neurocognition in bipolar I patients. $J$ Affect Disord. 2006;91(1):1-9.

16. David AS. Insight and psychosis. Br J Psychiatry. 1990;156: 798-808.

17. Ghaemi SN, Rosenquist KJ. Is insight in mania state-dependent?: a meta-analysis. J Nerv Ment Dis. 2004;192(11):771-775.

18. Cassidy F, Murry E, Forest K, Carroll BJ. Signs and symptoms of mania in pure and mixed episodes. J Affect Disord. 1998;50(2-3):187-201.

19. Cassidy F, Forest K, Murry E, Carroll BJ. A factor analysis of the signs and symptoms of mania. Arch Gen Psychiatry. 1998;55(1):27-32.
20. Cassidy F, Ritchie JC, Carroll BJ. Plasma dexamethasone concentration and cortisol response during manic episodes. Biol Psychiatry. 1998;43(10):747-754.

21. Cassidy F, Ahearn EP, Carroll BJ. Symptom profile consistency in recurrent manic episodes. Compr Psychiatry. 2002;43(3):179-181.

22. Cassidy F, Ahearn E, Murry E, Forest K, Carroll BJ. Diagnostic depressive symptoms of the mixed bipolar episode. Psychol Med. 2000;30(2):403-411.

23. Cassidy F, Carroll BJ. Seasonal variation of mixed and pure episodes of bipolar disorder. J Affect Disord. 2002;68(1):25-31.

24. Cassidy F, Ahearn E, Carroll BJ. A prospective study of inter-episode consistency of manic and mixed subtypes of bipolar disorder. $J$ Affect Disord. 2001;67(1-3):181-185.

25. Cassidy F, Carroll BJ. The clinical epidemiology of pure and mixed manic episodes. Bipolar Disord. 2001;3(1):35-40.

26. Cassidy F, Carroll BJ. Hypocholesterolemia during mixed manic episodes. Eur Arch Psychiatry Clin Neurosci. 2002;252(3):110-114.

27. Cassidy F, Wilson WH, Carroll BJ. Leukocytosis and hypoalbuminemia in mixed bipolar states: evidence for immune activation. Acta Psychiatr Scand. 2002;105(1):60-64.
Neuropsychiatric Disease and Treatment

\section{Publish your work in this journal}

Neuropsychiatric Disease and Treatment is an international, peerreviewed journal of clinical therapeutics and pharmacology focusing on concise rapid reporting of clinical or pre-clinical studies on a range of neuropsychiatric and neurological disorders. This journal is indexed on PubMed Central, the 'PsycINFO' database and CAS, and is the official

\section{Dovepress}

journal of The International Neuropsychiatric Association (INA). The manuscript management system is completely online and includes a very quick and fair peer-review system, which is all easy to use. Visit http://www.dovepress.com/testimonials.php to read real quotes from published authors. 